\title{
PENGEMBANGAN SISTEM INFORMASI DONOR DARAH BERBASIS WEB PADA UNIT TRANSFUSI DARAH KABUPATEN SUMEDANG
}

\author{
Rizal Rachman \\ STMIK Nusa Mandiri Jakarta \\ rizalkhaizuran@gmail.com
}

\begin{abstract}
Abstrak - Unit transfusi darah Kabupaten Sumedang merupakan satu-satunya pemasok kebutuhan darah untuk dua bank darah rumah sakit. Unit transfusi darah Kabupaten Sumedang memiliki tugas menyelenggarakan, mengatur, memfasilitasi kegiatan donor, persediaan darah dan pendistribusian darah. Dalam pelaksanaan tugasnya terdapat beberapa permasalahan yang sering terjadi seperti pada proses pencatatan data sering terjadi kesalahan, kehilangan atau kerusakan data, besarnya biaya yang dibutuhkan dalam pembuatan formulir dan peralatan alat tulis kantor. Permasalahan yang timbul disebabkan karena sebagian proses belum sepenuhnya terkomputerisasi. Untuk itu, dibutuhkan sistem informasi donor darah yang dapat membantu petugas unit donor darah dalam menjalankan tugasnya. Sistem informasi donor darah ini dibuat menggunakan model waterfall yang mencakup analisis, desain, pengkodean dan pengujian. Web Sistem informasi donor darah dibuat dengan menggunakan frame work codeigniter, sedangkan untuk bahasa pemrogramannya menggunakan PHP, Javascipt, CSS dan penyimpanan basis data MySQL. Dari hasil penelitian yang dibuat dapat menjadi alat bantu bagi user dalam mengolah data dan transaksi, tingkat keakuratan data dan informasi lebih tinggi dan dapat meminimalisir pengeluaran biaya, data transaksi lebih aman dan mudah diakses karena sudah menggunakan sistem berbasis web yang terintegrasi dengan database yang terhubung ke jaringan internet.
\end{abstract}

Kata kunci : Pengembangan sistem informasi, Donor Darah, WEB

\begin{abstract}
The blood transfusion unit of Sumedang Regency is the only supplier of blood needs for two hospital blood banks. Sumedang district blood transfusion unit has the task of organizing, organizing, facilitating donor activities, blood supply and blood distribution. In carrying out its duties, there are several problems that often occur, such as in the process of recording data, frequent errors, loss or damage of data, the amount of costs required in making forms and office stationery equipment. Problems that arise due to some processes not yet fully computerized. For this reason, a blood donor information system is needed that can assist blood donor unit officers in carrying out their duties. This blood donor information system was created using a waterfall model which included analysis, design, coding and testing. Web The blood donor information system is created using frame work codeiter, while for the programming language uses PHP, Javascipt, $\neg$ CSS and MySQL database storage. From the results of the research made can be a tool for users in processing data and transactions, the level of accuracy of data and information is higher and can minimize costs, transaction data is safer and easier to access because it uses a web-based system that is integrated with databases connected to Internet Network
\end{abstract}

Keywords : Development of information systems, Blood Donors, WEB

\section{PENDAHULUAN}

Unit Transfusi Darah (UTD) Palang Merah Indonesia (PMI) merupakan sebuah lembaga yang menyelenggarakan, mengatur, memfasilitasi kegiatan donor darah, persediaan darah dan pendistribusian darah (Permenkes, 2015). Di dalam penyelenggaraan pelayanan donor darah terdapat beberapa kegiatan yaitu pendataan pendonor, penerimaan darah, permintaan darah dan pendataan stok atau ketersediaan darah (Sophian, 2016). Data dari beberapa proses transaksi akan dikumpulkan dan selanjutnya diolah menjadi informasi untuk keperluan dan kepentingan pihak unit transfusi darah, relawan dan pihak bank darah rumah sakit.

Unit transfusi darah Kabupaten Sumedang merupakan lembaga yang bergerak di bawah naungan Palang Merah Indonesia (PMI) tingkat kabupaten atau kota dan menjadi satu-satunya pemasok kebutuhan darah untuk dua bank darah rumah sakit yang berada di Kabupaten Sumedang. Sudah tentu, dengan adanya unit transfusi darah ini sangat berguna bagi masyarakat Kabupaten Sumedang yang membutuhkan transfusi darah untuk keperluan medis. Namun sangat disayangkan, dalam pelaksanaan tugasnya terdapat beberapa permasalahan atau kendala yang sering terjadi. Permasalahan yang terjadi di lingkungan kerja unit transfusi darah dianggap dapat menghambat atau mengurangi kinerja pegawai bahkan dapat menyebabkan kerugian bagi pihak terkait.

Berdasarkan hasil dari wawancara yang dilakukan dengan pihak unit transfusi darah Kabupaten Sumedang, diperoleh beberapa penyebab terjadinya permasalahan yang sering terjadi. Adapun penyebabnya ialah, pada beberapa proses pencatatan data transaksi masih menggunakan cara manual atau belum sepenuhnya terkomputerisasi dengan baik, sehingga sangat besar kemungkinan terjadi kesalahan yang disebabkan oleh pegawai atau relawan yang dapat menyebabkan kerancuan data seperti data ganda. Untuk penyimpanan data transaksi juga masih menggunakan database lokal dan juga dokumen 
kertas yang sangat rentan terhadap kerusakan dan kehilangan data yang disebabkan oleh ulah manusia atau bencana alam seperti kebakaran. Selain itu, penyampaian informasi mengenai kegiatan donor dan jumlah stok darah masih menggunakan media telepon sehingga belum dapat menjangkau masyarakat luas atau pihak yang berkepentingan.

Penerapan sistem informasi berbasis web dirasakan sangat tepat diterapkan pada unit transfusi darah Kabupaten Sumedang, karena dengan menggunakan sistem informasi berbasis web dapat memudahkan dan mempercepat pihak unit transfusi darah, pihak BDRS (Bank Darah Rumah Sakit) maupun relawan dalam melakukan kegiatan seperti pendaftaran donor, pendataan relawan, penerimaan darah, permintaan darah dan pengeluaran darah. Selain itu, sistem informasi berbasis web juga dapat menghemat biaya pembelian kertas dan menjaga data dari kerusakan maupun kehilangan data yang diakibatkan oleh bencana alam maupun ulah manusia (Ali, 2015).

\section{KAJIAN PUSTAKA DAN PERUMUSAN HIPOTESIS}

Pemakaian informasi merupakan suatu komponen yang tidak dapat dipisahkan dari pengelolaan sistem informasi, karena sistem informasi berfungsi mendayagunakan informasi tersebut sesuai dengan kebutuhannya. Sistem adalah kumpulan elemen yang saling berhubungan dan berinteraksi dalam satu kesatuan untuk menjalankan suatu proses pencapaian suatu tujuan utama (Sutarman, 2012), Sistem adalah kumpulan atau bagian dari komponen yang saling berhubungan satu sama lain dan bekerja sama secara harmonis untuk mencapai suatu tujuan (Darmawan, 2013).

Web adalah sebuah sistem informasi yang disajikan dalam bentuk text, gambar, suara, dan lain-lain yang tersimpan dalam sebuah server Web Internet yang disajikan dalam bentuk hipertext (Simarmata, 2010). Sedangkan web adalah fasilitas hypertext yang mampu menampilkan data berupa teks, gambar, suara, animasi, dan multimedia (Dipraja, 2013).

$W e b$ adalah rangkaian program yang tersusun secara sistematis yang mampu menampilkan data berupa teks, gambar, animasi, dan suara. Ada beberapa fasilitas yang diperlukan untuk dapat mengakses atau menggunakan web atau website diantaranya internet merupakan singkatan dari interconnection-networking, pengertian harfiahnya ialah sistem global dari seluruh jaringan komputer yang saling terhubung menggunakan standar internet protocol suite (TCP/IP) untuk melayani miliaran pengguna di seluruh dunia (Yatingingsih, 2013).

Web browser adalah program komputer yang digunakan untuk membaca HTML, kemudian menerjemahkan dan menampilkan hasilnya secara visual ke layar komputer (Hidayatullah \& Jauhari,
2014). Web browser adalah aplikasi perangkat lunak yang digunakan untuk mengambil dan menyajikan informasi web (Sibero, 2013). Web server adalah perangkat lunak yang berfungsi menerima permintaan (request) berupa halaman web melalui HTTP atau HTTPS dari klien yang dikenal dengan browser web dan mengirimkan kembali (response) hasilnya dalam bentuk halaman-halaman web yang umumnya berbentuk dokumen HTML (Mulhim, 2013).

Hasil penelitian terdahulu yang pertama oleh (Ali, 2015) meneliti tentang kesenjangan fasilitas layanan rumah sakit yang ada di Bangladesh. Jika seseorang membutuhkan transfusi darah, pihak keluarga pasien akan mencari pendonor dari anggota keluarga yang lain, rumah sakit lain atau bank darah terdekat. Hal ini tentunya membutuhkan waktu yang lama sehingga menyulitkan pihak pasien. Selain itu, dengan sistem yang sedang berjalan saat ini, membutuhkan banyak waktu dalam pengambilan data dan pembuatan laporan. Dari hasil penelitian yang dilakukan, dihasilkan sebuah aplikasi berbasis web yang dapat memberikan informasi stok darah secara cepat, mempermudah dalam pengolahan data dan laporan. Dengan aplikasi yang dihasilkan juga dapat mempermudah bagi calon pendonor dalam mendaftarkan diri.

Hasil penelitian terdahulu yang kedua yaitu (Sophian, 2016) telah melakukan penelitian dengan menjadikan palang merah Indonesia sebagai objek penelitian. Adapun latar belakang masalah yang mendasari dilakukannya penelitian tersebut karena terjadi kerancuan data stok dan jenis darah disebabkan kesalahan input, proses pendataan yang dilakukan secara manual sehingga data tidak tersusun rapi, pengolahan sehingga untuk membuat laporan harian, mingguan dan bulanan memakan waktu yang cukup lama dan proses penyimpanan data masih dilakukan secara manual sehingga rentan terjadi kerusakan terhadap data. Dari penelitian yang dilakukan menghasilkan sebuah sistem berbasis desktop yang berguna untuk memudahkan pihak admin untuk melakukan pendataan dan pengolahan data. Dengan aplikasi yang dihasilkan dapat meminimalisir kesalahan dan mempercepat kerja pihak PMI.

Hasil penelitian terdahulu yang ketiga yaitu (Gustaman, Hidayat, \& Nurul, 2016) telah melakukan penelitian tentang sistem informasi donor darah. Masalah yang diangkat dalam penelitian tersebut ialah rendahnya kesadaran masyarakat dalam mendonor darah, sulitnya mendapatkan informasi stok darah baik di BDRS maupun di PMI, tingginya keraguan kualitas darah yang ada di PMI oleh pasien. Pendekatan dalam pembangunan perangkat lunak yang digunakan adalah Extreme Programming $(X P)$ dengan empat tahapan yaitu Planning, Design, Coding, Testing. Hasil dari penelitian ini adalah metode XP (Extreme Programming) dalam membuat 
aplikasi Transaction Processing System (TPS) dan Aplikasi SMS Gateway melibatkan satu admin dan banyak user (pasien). Teknologi SMS Gateway memudahkan pasien dalam mendapatkan informasi stok darah yang diinginkan. Durasi hak akses oleh pasien harus dibatasi berdasarkan wewenang dokter.

\section{METODE PENELITIAN}

Dalam melakukan penelitian ini terdapat beberapa teknik pengumpulan data yang dilakukan secara bertahap agar data yang diperoleh akurat. Adapun teknik pengumpulan data yang digunakan dalam penelitian ini sebagai berikut:

\section{a. Teknik Pengumpulan Data}

Teknik pengumpulan data yang digunakan adalah observasi, wawancara dan studi pustaka.

\section{Observasi (Pengamatan Langsung)}

Pada penelitian ini penulis melakukan pengamatan langsung terhadap objek penelitian yaitu PMI Kabupaten Sumedang untuk melihat langsung kondisi yang sebenarnya dengan maksud data yang diperoleh lebih akurat.

\section{Wawancara}

Selain melakukan observasi, penulis juga melakukan wawancara kepada pihak PMI khususnya staf UTD dan relawan dengan mengajukan pertanyaanpertanyaan yang berkaitan dengan permasalahan yang diangkat.

\section{Studi Pustaka}

Pada penelitian ini penulis juga melakukan studi pustaka untuk mencari teori-teori pendukung yang berkaitan dengan judul penelitian baik dari buku, jurnal maupun Internet.

\section{b. Model Pengembangan Sistem}

Pada pengembangan aplikasi ini, penulis menggunakan metode waterfall atau sering disebut model air terjun. Model waterfall adalah model yang paling sederhana di dalam pengembangan perangkat lunak. Untuk spesifikasi yang tidak berubah sangat cocok menggunakan model waterfall. Model yang digunakan pada pengembangan perangkat lunak ini menggunakan model waterfall yang terbagi menjadi 5 tahapan, yaitu:

\section{Analisis Kebutuhan}

Agar sistem yang dibuat sesuai dengan kebutuhan user maka penulis melakukan wawancara kepada pihak unit transfusi darah dan beberapa orang relawan untuk mengumpulkan informasi yang dibutuhkan dalam pembuatan sistem. Selain melakukan wawancara, penulis juga melakukan observasi langsung ke unit transfusi darah dengan mengamati proses kegiatan dan dokumen-dokumen masukan maupun keluaran sebagai acuan dalam membuat sistem.

\section{Desain}

Pada tahap desain penulis merancang desain interface dan sistem sesuai dengan kebutuhan user berdasarkan hasil analisis kebutuhan. Adapun desain interface meliputi desain form pendaftaran, form login, form permintaan darah, form berita acara pengiriman, form kelola donor, hingga form riwayat donor. Dan untuk desain sistem meliputi pembuatan Entity Relational Diagram (ERD), Logical Relational Structure (LRS) dan, Undifined Model Language (UML).

\section{Code Generation}

Pada tahap ini penulis menerjemahkan desain yang telah dibuat ke dalam program komputer atau dalam bahasa lain pembuatan kode-kode menggunakan bahasa pemrograman seperti PHP, CSS dan Javascript agar dapat menghasilkan sebuah program komputer sesuai desain yang telah dibuat.

\section{Testing}

Pada tahapan testing penulis melakukan percobaan atau pengecekan langsung terhadap program untuk memastikan program berjalan sesuai kebutuhan dan fungsinya serta bebas dari kesalahan. Adapun teknik pengujian yang digunakan adalah black box testing pengujian kepada fungsi program.

\section{Implementasi}

Pada tahap ini penulis mengimplementasikan program yang telah dibuat dengan mengupload filefile website ke houseting quord.com yang tela disewa dengan nama domain www.utdkabsumedang.com.

\section{ANALISIS DAN PERANCANGAN}

Berdasarkan uraian permasalahan pada bab sebelumnya maka penulis memberikan alternatif pemecahan masalah dengan membuat website sistem informasi donor darah. Dalam sistem yang dibuat relawan dapat melakukan pendaftaran donor, melihat riwayat donor. Dengan sistem ini juga petugas unit transfusi darah dapat melakukan konfirmasi donor, menambah jadwal donor, mengirim berita acara pengiriman darah sedangkan petugas rumah sakit dapat melakukan permintaan darah.

Berikut adalah tahapan analisis, desain database, menggunakan Entity Relationship Diagram (ERD) dan Logical record structure (LRS) untuk rancangan program usulan menggunakan Use case diagram dan user interface pada website sistem informasi donor darah unit transfusi darah Kabupaten Sumedang:

\section{a. Tahapan Analisis}

Adapun aktivitas yang berhubungan dengan kegiatan transfusi darah seperti pendaftaran donor, permintaan darah untuk transfusi, permintaan darah untuk BDRS 
( Bank Darah Rumah Sakit), menampilkan stok darah dan jadwal donor darah Berikut spesifikasi (system requirement) dari aplikasi web pengolahan nilai siswa:

1) Relawan

a) Relawan dapat membaca profil Palang Merah Indonesia Unit Kabupaten Sumedang.

b) Relawan dapat membaca artikel artikel disediakan

c) Relawan dapat melihat jadwal donor darah yang disediakan

d) Relawan dapat melihat stok darah yang terkini.

e) Relawan dapat membaca berita-berita dan melihat galeri foto.

f) Relawan dapat melakukan pendaftaran atau registrasi.

g) Relawan dapat melakukan pendaftaran donor.

h) Relawan dapat melihat riwayat donor.

i) Relawan dapat melihat biodata diri dan edit biodata.

2) Petugas Pelayanan Donor

a) Petugas pelayanan dapat mengelola jadwal donor darah.

b) Petugas pelayanan dapat melihat data relawan.

c) Petugas pelayanan dapat mengelola data donor.

3) Petugas Pelayanan Darah

a) Petugas pelayanan darah dapat melihat data permintaan darah.

b) Petugas pelayanan darah dapat konfirmasi permintaan dan kirim BAP.

c) Petugas pelayanan darah dapat melihat data pengiriman darah.

4) Petugas BDRS

a) Petugas BDRS dapat melakukan permintaan darah untuk BDRS.

b) Petugas BDRS dapat melihat data permintaan dan penerimaan darah.

5) Admin

a) Admin dapat mengolah data relawan dan semua petugas donor darah

b) Admin dapat mengolah semua data jadwal donor darah.

c) Admin dapat mengolah data berita dan data galeri.

d) Admin dapat mengolah data profile

e) Admin dapat mengamankan dan mengubah username dan password kalau ada permintaan supaya aman.

f) Admin dapat melihat semua laporan dan perubahan semua laporan

\section{b. Desain Rancangan}

Untuk gambaran jelas tentang website dibutuhkan rancangan sistem dan rancangan database. Berikut rancangannya:
1) Rancangan Sistem

Rancangan sistem diimplementasikan pada use case diagram relawan dan petugas donor pada gambar 1. sebagai berikut :

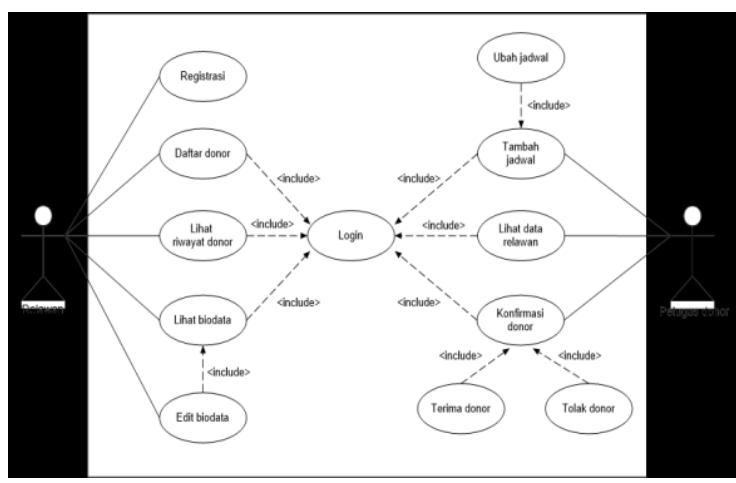

Gambar 1. use case diagram relawan dan petugas donor

Gambar 1 menjelaskan relawan dan petugas donor saling berinteraksi melakukan login pendaftaran, lihat riwayat donor, lihat biodata relawan sesuai sistem kebutuhan supaya berjalan tepat dan efektif.

Rancangan sistem selanjutnya diimplementasikan pada use case diagram petugas pelayanan darah dan petugas BDRS pada Gambar 2. sebagai berikut :

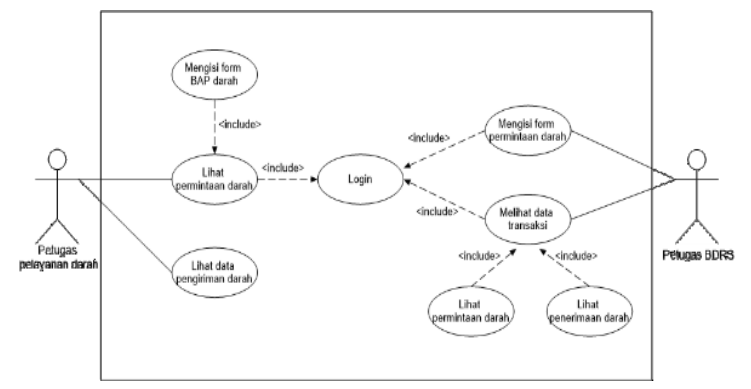

Gambar 2. Use Case Diagram Petugas Pelayanan Darah dan Petugas BDRS

Gambar 2. menjelaskan interaksi petugas pelayanan darah dan petugas pelayanan darah tentang

Pengisian form BAP, pengiriman darah dan penerimaan darah sesuai kebutuhan sistem.

2) Rancangan database

Rancangan database yang digunakan oleh penelitian ini adalah ERD dan LRS

\section{a) Entity Relationship Diagram (ERD)}

Gambar Entity Relationship Diagram (ERD) sistem usulan dapat dilihat pada Gambar 3. Pada gambar tersebut,terdapat sejumlah tabel yang saling memiliki relasi antara yang satu dengan yang lainnya. 


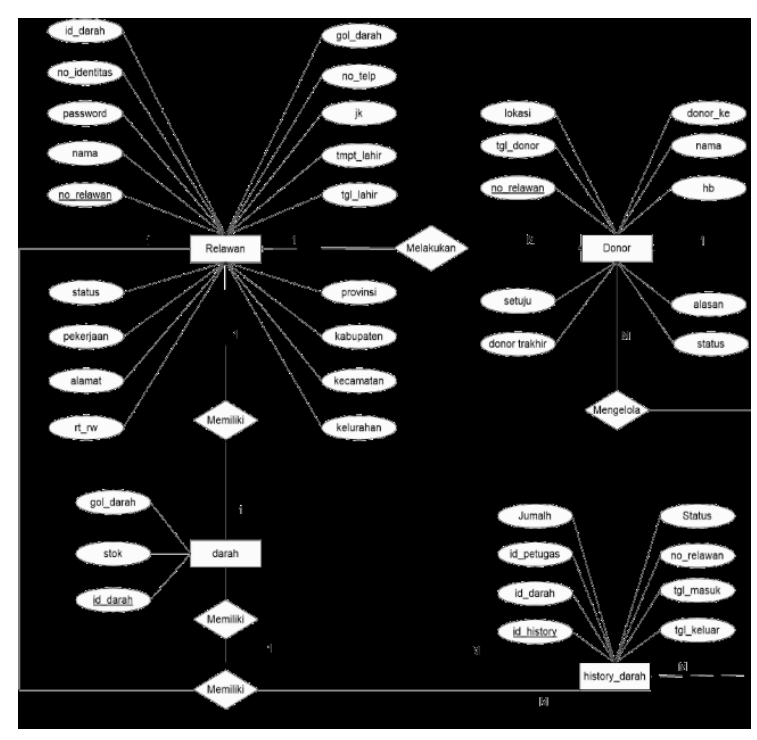

Gambar 3. Entity Relationship Diagram (ERD)

Tabel relawan memiliki keterkaitan dengan semua tabel, hal ini dikarenakan tabel relawan memiliki satu atribut primary key dan enam belas atribut foreign key yang berhubungan dengan atribut primary key tabel lain agar menghindari pengulangan data.

\section{b) Logical Record Structure (LRS)}

Gambar Logical Record Structure (LRS) sistem usulan dapat dilihat pada Gambar 4.

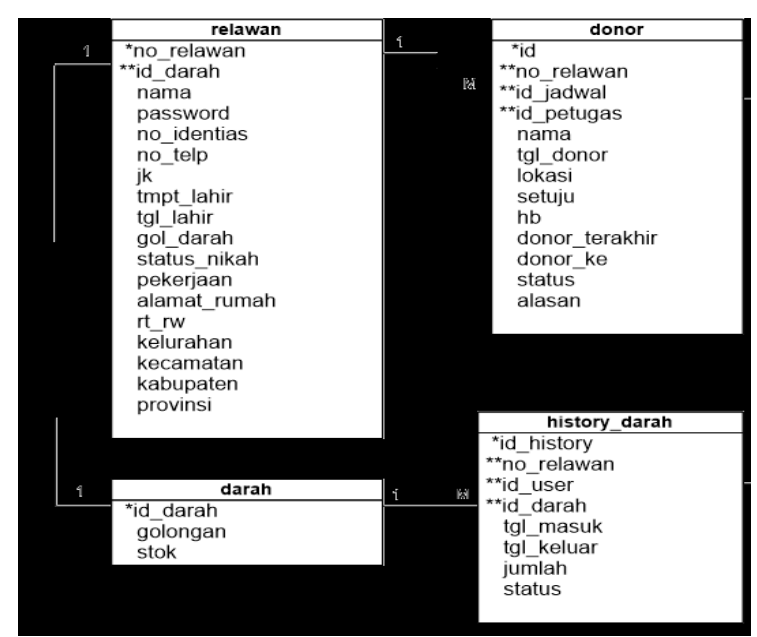

Gambar 4. Logical Record Structure (LRS)

Gambar 4 merupakan representasi basis data sistem informasi donor darah unit transfusi darah Kabupaten Sumedang sehingga memudahkan sistem untuk mencari data, menghapus, dan memperbarui data.

\section{c. User Interface}

Adapun tampilan sistem informasi donor darah pada unit transfusi darah Kabupaten Sumedang sebagai berikut :

1) Halaman Utama Sistem Informasi Donor Darah

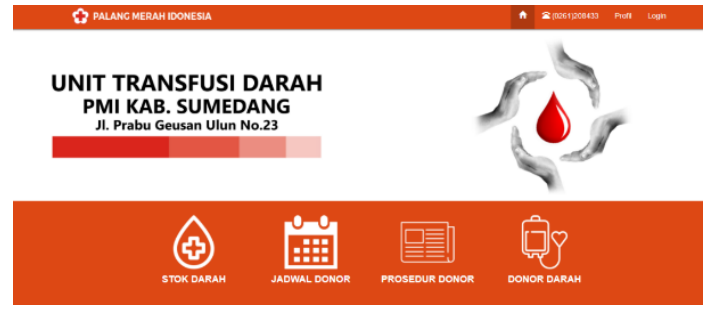

Gambar 5. Halaman Utama Sistem Informasi Donor Darah

Gambar 5. Menjelaskan Halaman utama berisi judul sistem informasi dan logo donor darah dilengkapi menu stok darah, jadwal donor, prosedur donor dan donor darah untuk bisa link ke tahap transaksi sebelumnya.

2) Halaman Stok Darah UTD Kab. Sumedang Menampilkan persediaan darah UTD Kab. Sumedang. Gambar halaman stok darah dapat dilihat pada Gambar 6.

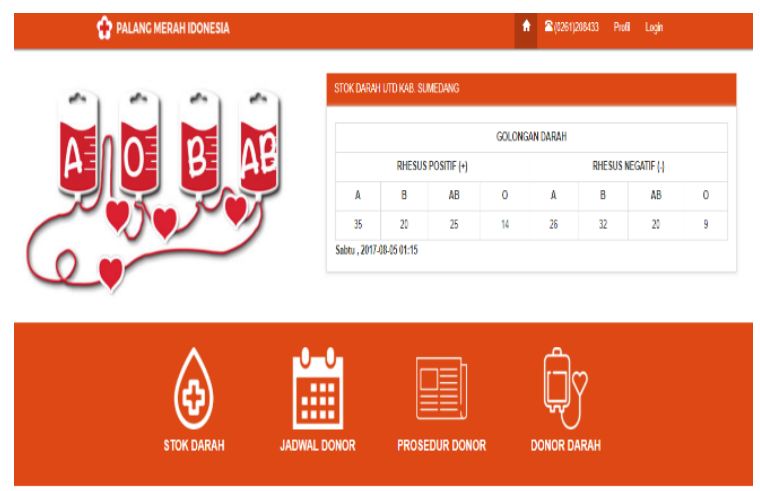

Gambar 6. Halaman Stok Darah UTD Kab. Sumedang

Gambar 6 menjelaskan informasi dari UTD Kabupaten Sumedang tentang persediaan stock darah up to date.

3) Halaman Jadwal Donor

Menampilkan jadwal donor darah UTD Kab. Sumedang. Halaman jadwal donor darah dapat dilihat pada Gambar 7.

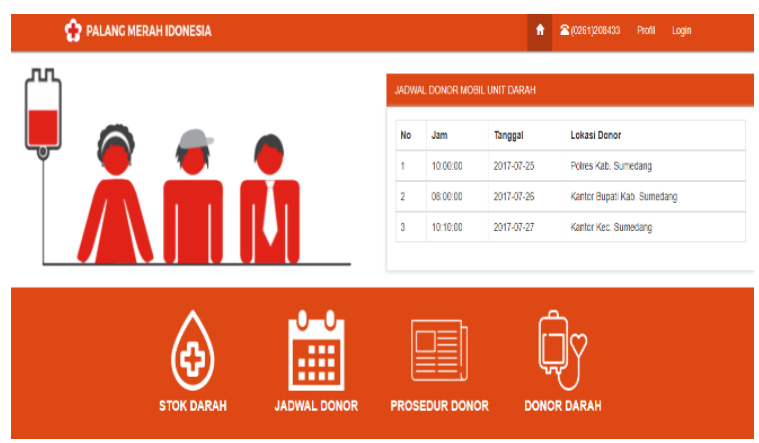

Gambar 7. Halaman Jadwal Donor 
diharapkan tanpa memperhatikan struktur internal atau logika pemrograman yang digunakan. Hasil dari pengujian black box testing sistem informasi donor darah berbasis web dapat dilihat pada Tabel 1.

Tabel 1. Hasil Pengujian Black Box Testing Form Daftar Relawan

\begin{tabular}{|c|c|c|c|c|}
\hline $\begin{array}{l}\text { Sekenario } \\
\text { pengujian }\end{array}$ & $\begin{array}{l}\text { Tets } \\
\text { case }\end{array}$ & $\begin{array}{c}\text { Hasil } \\
\text { yang } \\
\text { diharap } \\
\text { kan }\end{array}$ & $\begin{array}{l}\text { Hasil } \\
\text { peng } \\
\text { ujian }\end{array}$ & $\begin{array}{c}\text { Kesimp } \\
\text { ulan }\end{array}$ \\
\hline $\begin{array}{l}\text { Mengoson } \\
\text { gkan } \\
\text { semua } \\
\text { inputan } \\
\text { pada form } \\
\text { kemudian } \\
\text { klik } \\
\text { tombol } \\
\text { daftar }\end{array}$ & $\begin{array}{l}\text { Semu } \\
\text { a } \\
\text { input } \\
\text { pada } \\
\text { form : } \\
\text { (koso } \\
\text { ng) }\end{array}$ & $\begin{array}{l}\text { Sistem } \\
\text { tidak } \\
\text { dapat } \\
\text { menyim } \\
\text { pan data } \\
\text { dan } \\
\text { auto } \\
\text { fokus ke } \\
\text { inputan } \\
\text { yang } \\
\text { kosong }\end{array}$ & $\begin{array}{l}\text { Sesua } \\
\mathrm{i} \\
\text { harap } \\
\text { an }\end{array}$ & Valid \\
\hline
\end{tabular}

Tabel 1 menjelaskan tentang pengujian daftar relawan untuk menginputkan biodata diri dan spesifikasi donor darah untuk mengurangi kesalahan.

\section{f. Supporting}

\section{1) Publikasi web}

Merupakan proses upload file-file dari sebuah website yang telah dibuat ke dalam web hosting agar file-file dapat diakses oleh user melalui perangkat komputer atau smartphone yang terhubung dengan jaringan internet. Dalam publikasi website unit transfusi darah kabupaten sumedang penulis menyewa web hosting dari quord.com dengan domain http://www.utdkabsumedang.com.

Tabel 2. Spesifikasi Hardware dan Software

\begin{tabular}{|c|c|}
\hline Kebutuhan & Keterangan \\
\hline Sistem Operasi & Windows XP \\
\hline Processor & $\begin{array}{c}\text { AMD Dual-core } \\
\text { Prosessor C60 }\end{array}$ \\
\hline RAM & 2 MB \\
\hline Hard Disk & $320 \mathrm{~GB}$ \\
\hline Monitor & LCD 11" \\
\hline Keyboard & Standar \\
\hline Mouse & Standar \\
\hline Browser & $\begin{array}{c}\text { Semua Browser yang } \\
\text { mendukung HTML5 }\end{array}$ \\
\hline
\end{tabular}

Tabel 2 menjelaskan spesifikasi yang dibutuhkan untuk menjalankan sistem informasi donor darah UTD Kabupaten Sumedang.

\section{2) Spesifikasi Hardware dan Software}

Digunakan untuk menjalankan atau mengakses sistem informasi donor darah berbasis web dapat dilihat pada Tabel 2 .

\section{3) Spesifikasi Dokumen Sistem Usulan}

Nama Dokumen : Formulir Pendaftaran relawan Fungsi : Input data relawan

Sumber : : Sistem informasi donor darah

Tujuan : Petugas pelayanan donor

Media : File

Frekuensi : Setiap pendaftaran baru

Format : Lampiran B.1.

\section{KESIMPULAN DAN SARAN}

\section{Kesimpulan}

Berdasarkan dari pembahasan pada bab sebelumnya dan sistem yang telah dibuat. Adapun kesimpulan yang diambil sebagai berikut:

1. Sistem informasi yang dibuat dapat menjadi alat bantu bagi user dalam mengolah data dan transaksi.

2. Dengan menggunakan sistem informasi ini, tingkat keakuratan data dan informasi lebih tinggi dan dapat meminimalisir pengeluaran biaya dalam pembuatan formulir dan pembelian kertas.

3. Data transaksi unit transfusi darah Kabupaten Sumedang dapat disimpan dengan aman dan mudah diakses karena sudah menggunakan sistem berbasis web yang terintegrasi dengan database yang terhubung ke jaringan internet.

\section{Saran}

Dalam pembuatan sistem informasi donor darah pada unit donor darah Kabupaten Sumedang tentunya tidak lepas dari kekurangan dan kelemahan. Oleh karena itu, penulis memberi beberapa saran untuk keperluan pengembangan sistem kedepanya. Adapun saran dari penulis sebagai berikut :

1. Menambahkan fungsi cetak laporan pada setiap transaksi agar data atau informasi dapat dicetak ke dalam bentuk hard copy.

2. Menambahkan form permohonan kegiatan donor untuk memudahkan instansi maupun relawan untuk mengajukan kegiatan donor. 


\section{DAFTAR PUSTAKA}

Ali, K. A. (2015). Blood Donation Management System. American Journal of Engineering Research (AJER) e-ISSN: 2320-0847 pISSN : 2320-0936. Volume-4, 123-136.

Darmawan. (2013). Sistem Informasi Manajemen. Jakarta: Remaja Rosdakarya.

Dipraja, S. (2013). Panduan Praktis Membuat Website Gratis. Depok: Pustaka Makmur.

Gustaman, R. A., Hidayat, E. W., \& Nurul, H. (2016). Sistem Informasi Pelayanan Donor Darah Berbasis Web(Studi Kasus: Pmi Tasikmalaya). STMIK AMIKOM Yogyakarta. ISSN : 2302-3805.

Hidayatullah, P., \& Jauhari, K. (2014). Pemrograman Web. Informatika: Kawisatra.

Mulhim, I. (2013). Aplikasi toko bangunan online dengan PHP dan MySQL. Palembang: Maxikom.

Permenkes. (2015). Tentang Standar Pelayanan Transfusi Darah. Jakarta.

Sibero, A. (2013). Web Programming. Yogyakarta: Madiakom.

Simarmata, J. (2010). Rekayasa Web. Yogyakarta: Andi Offset.

Sophian. (2016). Sistem Informasi Palang Merah Indonesia (PMI) Dengan Menggunakan Visual Basic.Net. Jurnal Edik Informatika. Vol 2, 182-203.

Sutarman. (2012). Penghantar teknologi Informasi. Jakarta: Bumi Aksara.

Yatingingsih, F. (2013). Step by step belajar komputer dan internet. Yogyakarta: Buku Pintar. 